\title{
Intersection and Integration: Interdisciplinary Design Practice and New Media Art Design Teaching
}

\author{
Zhijun Wang, ${ }^{1, *}$ \\ ${ }^{1}$ Academy of Fine Arts, Shanxi University, Taiyuan, Shanxi 030006, China \\ *Corresponding author. Email: duchy777@163.com
}

\begin{abstract}
Interdisciplinary research is a new model of knowledge innovation research for a single subject. Increasingly, many interdisciplinary researches have shown multi levels and forms, ranging from simple exchange of academic ideas to comprehensive exchanges or even integration of academic views, methods, procedures, understanding, concepts, etc. of different disciplines. In recent years, the education circle has been continuously discussing the interdisciplinary issues of art design teaching. For art teachers, how to apply scientific and effective teaching methods to curriculum design from the standpoint of professional autonomy is truly an important issue [1]. Based on this trend and demand and interdisciplinary research theory, combined with the current situation of visual culture and art education, this paper explores the new mode of curriculum design in the teaching of new media art design. Taking interdisciplinary teaching and research on new media art design as a mode and a practice, it would correspond to the development trend of knowledge, change people's way of thinking, and achieve new breakthroughs in teaching research and practice of new media art design.
\end{abstract}

Keywords: Interdisciplinary research, New media art, Concept development, Training model.

\section{INTRODUCTION}

New media art is an interdiscipline based on the concept of creation, combining computer science, high-tech materials, biology, chemistry, physics, psychology, vision, performance and other subjects in many fields. In real culture, new media art widely affects people's ideas, values and ideology. Michelle Rouch defined new media art as technology-based art in her book "New media in art in the late 20th century". The author believes that "new media" is a changing concept relative to "old media". It can be regarded as an information communication means that breaks through the boundaries of art and depends on new technology. Since the birth of mankind, human society has experienced at least four significant information communication revolutions. Each information communication revolution has pushed human civilization to a new stage of development. The latest information communication revolution, that

*Fund: This paper is supported by the results of 2018 Shanxi Soft Science Research Project (2018041038-1). is, the fifth information communication revolution taking place around human beings, is the birth of digital electronic communication. Nowadays, all kinds of information transmission modes with clear boundaries in the past, such as numbers, languages, words, sounds, pictures and images, which represent and record the human material and spiritual world, can be digitally processed in computer language. The differences between the forms of traditional mass media are narrowing or disappearing. The emergence of interactive communication media has brought mankind into the real information age. In order to meet the requirements of contemporary information communication, art design began to seek multidisciplinary technology integration on the basis of traditional technology. Three dimensional devices, new materials, interactive technology, dynamic images, sound effects and even smell and temperature are increasingly used in the creation of media art design, in order to start the audience's various sensory nerves by building a comprehensive experiential information 
communication framework, effectively convey information and realize emotional docking [2].

\section{INTERDISCIPLINARY AND ITS CONCEPT INTRODUCTION IN NEW MEDIA ART}

According to the latest definition of the National Academy of Sciences, interdisciplinary research is a research model of teams or individuals. It integrates information, data, technology, tools, views, concepts and theories from more than two disciplines or professional knowledge groups to promote basic understanding or solve problems that cannot be solved by a single discipline or research field. The interdiscipline refers to "a new discipline formed by the combination, penetration and intersection of two or more disciplines." Interdisciplinary and interdiscipline concepts are often mixed in Chinese literature, which reduces the inheritance of theoretical development and the ability to explain reality. Here, the author first gives a more scientific definition of these two concepts, then summarizes the relationship between them, reveals the characteristics of different interdisciplinary development stages, and finally discriminates the concept of discipline convergence.

As for the interdisciplinary issue of art and design, Tan Ping believes that the integration of disciplines is a topic of special concern. Its significance for innovation is not temporary thinking, but a breakthrough point of value found in the relationship between disciplines, such as the architectural design of Water Cube and Bird's Nest. Interdisciplinary leapfrogging is not just an attempt, but an important part of knowledge structure, which is not static but dynamic. And it is jointly constructed by relevant knowledge. In 2006, the office of the Academic Degrees Committee of the State Council decided to revise the catalogue of disciplines and majors that have been implemented for nearly 10 years. In the research on the formulation of the new catalogue, how to set up interdiscipline has attracted great attention. Interdisciplinary research may not only occur within the existing single discipline system, but also between different disciplines. Interdisciplinary research presents increasingly multi levels and forms, ranging from simple exchange of academic ideas to comprehensive exchange or even integration of academic views, methods, procedures, understandings and concepts of different disciplines [3].
The professional characteristics of new media art determine that it is inseparable from the cooperation and integration between disciplines. New media art and visual language is a very broad proposition, involving all aspects of people's daily life. In the contemporary digital communication environment, due to the comprehensive use of computer technology, network and remote communication technology, the information characteristics of media show incomparable advantages over traditional media: the infinity of information, the interactivity of information transmission, and the wide coverage. In addition, in terms of communication, the expression form of new media art contains more technical components than traditional media, integrates the advantages of multimedia, has the real-time, dynamic and interactive characteristics, integrates the functions of text, sound, picture and animation, and enables the viewer to participate in changing the image, shape and even meaning of the work through direct interaction with the work.

\section{INTERDISCIPLINARY AND INTEGRATION: INTERDISCIPLINARY DESIGN PRACTICE}

Interdisciplinary research is a new model of knowledge innovation research for a single discipline. It occurs not only within the existing single discipline system, but also between different disciplines. Many interdisciplinary research presents more and more levels and forms, including simple exchange of academic ideas, comprehensive exchange or even integration of academic views, methods, procedures, understanding, concepts, etc. From the recent research in China and foreign countries, interdisciplinary can be understood in two ways. First is interdisciplinary practice, that is, a kind of research methods, research models or research organizations to promote the development of various fields of science and solve practical problems. Second is as a theory to explain interdisciplinary phenomena and guide the development of interdisciplinary practice. Roy Ascot, the pioneer of new media art, said that the most distinctive characteristics of new media art are connectivity and interaction [4]. Understanding new media art creation needs to go through five stages: connection, integration, interaction, transformation and emergence. Judging from the development trend of science, more and more creative contributions and important breakthroughs are produced in cross-discipline and cross-field 
collaboration. The state changing from knowledge division to knowledge integration is the knowledge state of interdisciplinary training mode. In the interdisciplinary training mode, the state and development trend of knowledge are obviously different from the previous single discipline training mode. In the previous single discipline training mode, knowledge is in a divided state, and this division becomes more and more intense with the development of the discipline. The knowledge in a discipline cannot be integrated with the knowledge outside the discipline, and the knowledge boundary between different branches of the same discipline is becoming clearer and clearer. This knowledge state has changed in the interdisciplinary training mode, that is, knowledge begins to move from division to integration.

Interdisciplinary research is a multi-level and multi-form research, and the possible forms of achievements are also diverse. For interdisciplinary research, at the beginning of problem research, the nature of the discipline involved, the span and convergence between disciplines can only be roughly framed, and then gradually clear in the process of exploration. The final result depends on the possible historical process of the internal logic of knowledge and the internal and external support conditions of the research. The approaches and effects of cross-disciplines can be divided into three modes: discipline penetration, discipline horizontal shift and discipline ascending [5]. Bernard Shapir, President of McGill University in Canada, pointed out: "in the field of universities, what has changed dramatically is the knowledge base itself. The change of knowledge has two characteristics. First, the most interesting research courses are more at the junction of traditional subjects; second, the balance between the system method and the reduction method gradually turns to the system method to study large and complex organisms and the demand for interdisciplinary research." It can be seen that whether in interdisciplinary research or interdisciplinary education, the boundary between knowledge of different disciplines will become more and more blurred, and the development of knowledge tends to be integrated. On the one hand, the fixed mode of single subject knowledge has been eliminated; on the other hand, the integration of knowledge of various disciplines is the general trend. Corresponding to this development trend of knowledge, people's way of thinking has also changed, resulting in a new breakthrough in the research and practice of art design.

\section{SIGNIFICANCE OF INTERDISCIPLINARY PRACTICE}

\subsection{Enriching the Beginning of People's Perception}

Rudolph Arnheim believes that art research should be an indispensable part of training in any other field of knowledge. A good teacher will make people aware of this connection in any flexible way to ensure that the social, historical or psychological materials he mentions to his students are not only the scholarly supplement to the teaching materials, but also play a practical role in the design itself. Therefore, for practical purposes, being familiar with the principles of art forms and the methods of expressing meaning according to these principles will directly contribute to the cultivation of creative thinking in any field. The wide application of new media technology in new media art breaks the restrictions of all media, and makes new media art obtain unprecedented expression space. People comprehensively use various effective media methods, providing the greatest possibility for the expression space of new media art.

\subsection{Deepening the Artistic Connotation of Works}

In Arnheim's view, one of the main functions of art is to help people's thinking cope with the complex image of the world and find themselves from it [6]. In the study of design, in addition to the design theory, design information books and other knowledge books people are interested in, they should read a lot of history books, Chinese and foreign philosophy, contemporary art and other books, which will make works be of more connotation and ideological power. Philosophy will give human beings a better perspective. Whoever has a vision will know the significance of correctly evaluating everything in this vision according to distance and size. In the process of a person's full development, new media art education should be used to enable students to have the basic skills needed to successfully express themselves. The first is philosophy, which trains students' logical thinking, cognitive ability and ethics. The second is visual training, which enables students to learn to deal with visual phenomena as the main way to deal with organized thinking. The third is language training, which enables students to communicate the results of their thinking in language. The expansion of interdisciplinary practice leads to continuous questioning of the existing knowledge 
to improve the understanding of the known [7], showing philosophical attitude and proposition that people attach importance to the expression of personal direct experience, and the intuitive examination of the value and significance of human life, as well as the attention to social, cultural and other issues.

\subsection{Concept Expansion and Visual Innovation}

A good designer is firstly a good thinker. Human beings are in an era of unprecedented visual wealth and visual tension in human history. Heidegger has predicted that human beings are entering a "world image era". Due to the support of network for multimedia technology, the means of visual communication are rich and diverse. From many new media art works, people can deeply feel the great impact of discipline crossing on the works. At the same time, discipline crossing brings conceptual changes to the development of art design. New ideas and means have brought new enlightenment to the works. Various works have created new visual forms with multi-perspective design thinking, and opened up multiple spaces of design thinking. It is suggested to record the development trend of contemporary art and culture through new media art design, build a platform for graphic communication and dialogue with visual language, mobilize all available media and means, and launch more dynamic and creative visual works by means of multimedia and cross media. Also, it tries to explore various possibilities and expansibility of visual communication and culture from different fields, so as to produce a new visual feeling beyond the boundaries of graphics.

\section{CONCLUSION}

The interdisciplinary leap brings not only the innovation of design concept. Through concept innovation, new ideas are given to design. People can find new perspectives with creative value from diversified choices, create distinctive design works, and make the design take on a new look. Secondly, there are innovations in the form of expression. The formal innovation comes from the thinking and enlightenment of artistic practice. The specific spiritual time and unique language characteristics are combined into a novel formal language, which has a novel visual feeling and good communication effect. What human beings need are not only graphics and images, but also more thinking about design from the design process and results. The
21 st century is a century of integration and inclusiveness. In the new century, it requires human beings to grasp a variety of communication media, communication methods and communication skills, and pay more attention to the future. Each course of art design education is centered on its own central structure. Whether it is art practice course or art history, each research field interacts with other fields. This relationship network constitutes the art system of human experience and wisdom. The application scope of digital environment will be wider and wider, there will be more and more products, and the influence will naturally be greater and greater. In the digital environment, the transformation of narrative language has become more diverse and interesting. More and more messages are used to communicate and exchange each other's ideas through pictorial language, and new visual methods and artistic language are constantly being created. "Through auditory, visual, conceptual, artistic and scientific insight, and visual language become the "decision maker" of design. And then, it profoundly changes people's view of the world and the future.

\section{AUTHORS' CONTRIBUTIONS}

This paper is independently completed by Zhijun Wang.

\section{REFERENCES}

[1] [U.K.] Herb Reed. Education through Art. Translated by Lu Tinghe Hunan: Hunan Fine Arts Publishing House 1995. (in Chinese)

[2] [America] Marjorie Elliott Beverlin. Introduction to Art Design. Translated by Sun Lining. Shanghai: Shanghai People's Fine Arts Publishing House, 2006, 1st edition. (in Chinese)

[3] Zhu Ming, Jing Lei. Design History. Shandong: Shandong Fine Arts Publishing House, 2004, 1st edition. (in Chinese)

[4] [U.K.] Roy Ascott.The Future is Now - Art, Technology, and Consciousness by Yuan xiaoying.Beijing: Jincheng Publishing House, 2012, 1st Edition. (in Chinese)

[5] Liu Zhonglin. Modern Interdiscipline [M]. Hangzhou: Zhejiang Education Press, 1998. (in Chinese)

[6] [America] Rudolf Arnheim. Visual Thinking. Translated by Teng Shouyao. Sichuan: 
Sichuan People's Publishing House, 1998, 1st Edition. (in Chinese)

[7] Chen Chan, Zou Xiaodong. Analysis the Nature and Significance of Interdiscipline [J]. Research and Development Management, 2006(2). (in Chinese) 